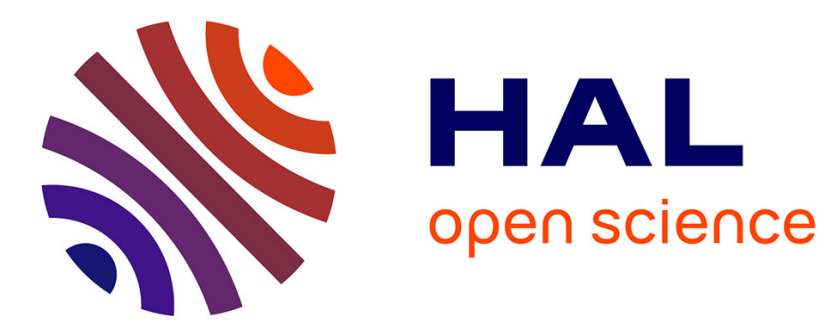

\title{
CW X-RAY PREIONIZED PULSED GAS LASERS
}

\author{
T. Arai, Y. Mori, Y. Imai, K. Sugino, M. Obara, T. Fujioka
}

\section{To cite this version:}

T. Arai, Y. Mori, Y. Imai, K. Sugino, M. Obara, et al.. CW X-RAY PREIONIZED PULSED GAS LASERS. Journal de Physique Colloques, 1980, 41 (C9), pp.C9-237-C9-242. 10.1051/jphyscol:1980931 . jpa-00220585

\section{HAL Id: jpa-00220585 https://hal.science/jpa-00220585}

Submitted on 1 Jan 1980

HAL is a multi-disciplinary open access archive for the deposit and dissemination of scientific research documents, whether they are published or not. The documents may come from teaching and research institutions in France or abroad, or from public or private research centers.
L'archive ouverte pluridisciplinaire HAL, est destinée au dépôt et à la diffusion de documents scientifiques de niveau recherche, publiés ou non, émanant des établissements d'enseignement et de recherche français ou étrangers, des laboratoires publics ou privés. 


\section{CW X-RAY PREIONIZED PULSED GAS LASERS}

T. Arai, Y. Mori, Y. Imai, K. Sugino, M. Obara and T. Fujioka

Department of Electrical Engineering, Keio University, 3-14-1, Hiyoshi, Kohoku-ku, Yokohama-shi, 223, Japan.

Abstract.- We have successfully demonstrated that the cw x-ray generator can work as a preionization source for a pulsed HF laser. The preionization effect of $\mathrm{cw} x$ radiation was revealed by a comparative study of with and without applying $\mathrm{x}$-ray photons to the HF laser. Since dose rate of the $\mathrm{cw}$ $x$-ray generator is easily controllable, the laser output could be measured as a function of initial electron number density produced. The $\mathrm{cw} x$-ray preionizer has many advantages for actual gas laser systems compared with other preionizers. There are attributable to its high-energy photons and its characteristics of the $\mathrm{cw}$-ray generator. Applicability of the $\mathrm{cw}$-ray preionizer for actual laser systems, especially for high-repetition-rate pulsed laser systems is discussed.

\section{INTRODUCTION}

We have first used a cw $x$-ray generator as a preionizer for pulsed-discharge gas lasers. The preionization by $\mathrm{CW} x$ radiation has a potential similar to that by the flash $x$-ray preionization for high pressure gas lasers. Since x-ray photons penetrate longer distance than uv photons, the $x$-ray preionization scheme is scalable against gas pressure and discharge volume. In addition, the cw $\mathrm{x}$-ray generator has a long operation lifetime (>1000 hours) which is being utilized for industrial application, and it gives a purely continuous preionization so that it can be used for ultra-high-repetition-rated $\left(<10^{5} \mathrm{~Hz}\right)$ operation. The $x$-ray flash preionizers have been successfully operated in a high pressure KrF laser, which was reported by Sumida et $a l^{1}$. and Lin et al. By using the x-ray flash preionizers, many advantages have been found for high-pressure pulseddischarge gas lasers. Although the $\mathrm{x}$-ray flash preionizer did not have sufficient durability $\left(<1000\right.$ shots $^{3}$ due to its anode evaporation by high current density, the cw $x$-ray generator has a long operating lifetime as a preionizer. Here, we want to report the preionization effect of $\mathrm{CW} x$ radiation on a pulsed-discharge initiated HF chemical laser.

\section{EXPERIMENTAL SETUP}

An industrial $\mathrm{cw} x$-ray tube (Hitachi SIO-100-5/Be), about 50-mm in diameter and $220-\mathrm{mm}$ in length, was used as the cw $\mathrm{x}$-ray generator. This ow x-ray tube consisted of a $1 \times 1 \mathrm{~mm}^{2}$ target on $\mathrm{Cu}$ anode, a hot cathode, and an $x$-ray exit window of Be of 1-mm thickness which allows low energy $x-$ ray photons less than $5 \mathrm{keV}$ to be transmitted to provide high $\mathrm{x}$-ray dose. Using a Victreen model 660-3 survey meter, an $\mathrm{x}$-ray dose rate of $125 \mathrm{R} / \mathrm{min}$. was measured at $30 \mathrm{~cm}$ away from the $\mathrm{cw} x$-ray exit window, under conditions where $\mathrm{cw} x$-ray 
tube voltage and current were $50 \mathrm{kV}$ and $2 \mathrm{~mA}$, respectively. Since this $\mathrm{x}$-ray survey meter can not detect photons less than $10 \mathrm{keV}$ due to the transmission characteristics of its incident window, practical dose rate is larger than the measured value. This $\mathrm{cW} x$-ray tube was immersed in a insulation oil bath for high voltage insulation and cooling. The $\mathrm{CW} x$-ray beam emitted from the tube was spread out with a half angle of 20 degress. This angle is mainly determined by the arrangement between the $x$-ray target and the $x$-ray exit window. The maximum input power into the tube was $500 \mathrm{~W}(100 \mathrm{kV}, 5 \mathrm{~mA})$. We used it at a tube voltage less than $60 \mathrm{kV}$ and a tube current less than $4 \mathrm{~mA}$. Under such a low input power condition, the lifetime of this cw $x$-ray tube would be over $3 \times 10^{3}$ hours, and even under the maximum rated conditions the nominal lifetime is longer than $10^{3}$ hours. A dc high voltage power supply was used as a acceleration potential of the cw $x-r a y$ tube.

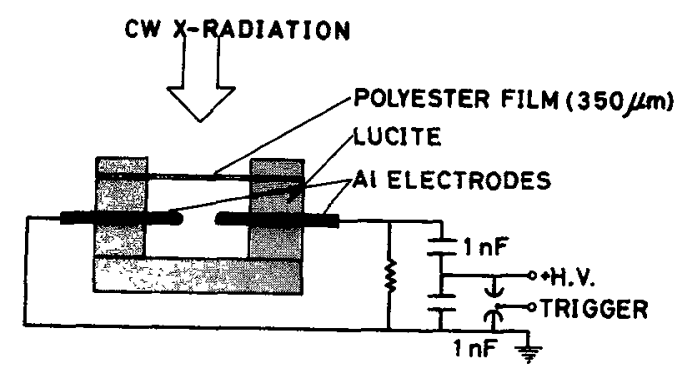

FIG. 1. Schematic drawing showing cross-sectional view of the laser chamber and discharge circuit.

The cross-sectional view of the laser chamber and the electrical circuitry for main discharge are illustrated in Fig. 1. The laser chamber envelope was made of Lucite plates, and both ends of the laser chamber were sealed with $\mathrm{CaF}_{2}$ windows. A

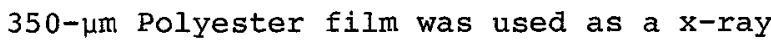
incident window allowing soft $x$-ray photons to be transmitted. The $x$-ray photons irradiated from the $\mathrm{cw} x$-ray tube was transmitted through the air to the laser chambex. In order to uniformly illuminate the entire discharge volume transversely, the laser chamber was placed $35 \mathrm{~cm}$ away from cw $x$-ray tube. The discharge electrodes, 3-mm thick and 280-mm long, were rounded on both corners to reduce field enhancement, and separated by a 10-mm interelectrode gap. The main discharge was driven by a L-C inversion circuit, consisting of low-inductance capacitors ( $1 \mathrm{nF}$ each), and a pressurized $\mathrm{N}_{2}$ spark gap. The laser discharge was fired once every 4 seconds because of the replenishment of the laser gas mixture during shot to shot intervals and due to the removal of influence of the aferglow of the previous shot. The laser gases $\left(\mathrm{C}_{4} \mathrm{H}_{10}\right.$ and $\left.\mathrm{SF}_{6}\right)$ were premixed and flowed into the laser chamber. The arrangement of the laser chamber and the $\mathrm{cw}$ $x$-ray generator is shown in Fig. 2. The laser cavity comprised an Au concave reflector and a flat $\mathrm{CaF}_{2}$ output coupler. The laser energy was measured by a GenTec ED-200 joule-meter.

\section{EXPERIMENTAL RESULTS AND DISCUSSION} The effect of the cw $x$-ray preionization on HF laser energy is shown in Fig. 3. The mixture of $\mathrm{C}_{4} \mathrm{H}_{10} / \mathrm{SF}_{6}=7 / 73$ was 
used, which gave the maximum laser energy.

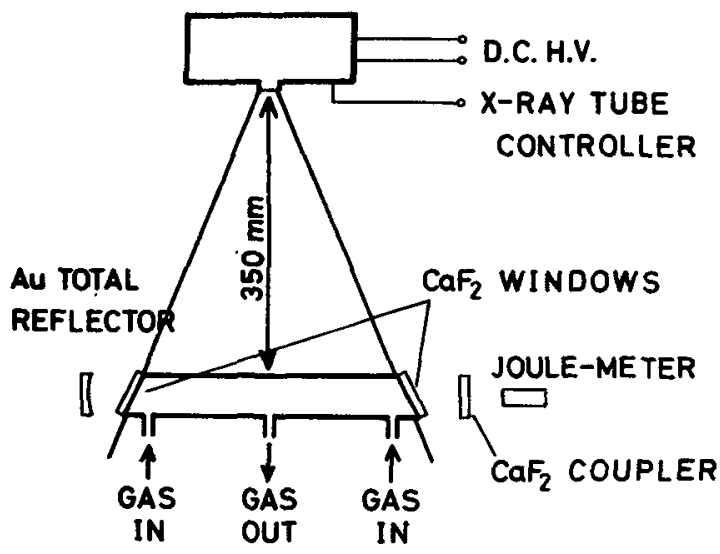

FIG. 2. Arrangement of the laser chamber and the cw x-ray preionizer.

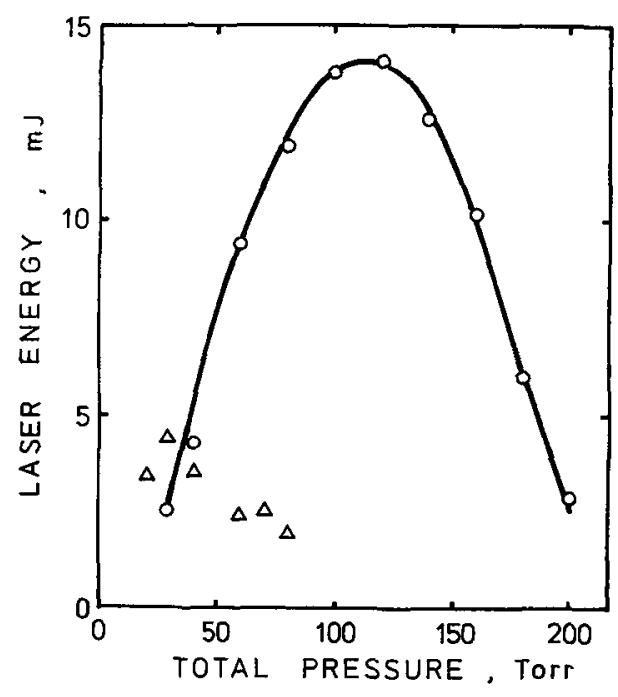
FIG. 3. Effect of $\mathrm{Cw} x$ radiation on $\mathrm{C}_{4} \mathrm{H}_{10} / \mathrm{SF}_{6}$
laser energy. $\mathrm{O}$ : with $\mathrm{cw} \times \mathrm{x}$ radiation,

$\Delta$ : without cw $x$ radiation (i.e. without any preionizers). cw $\mathrm{x}$-ray tube voltage, $50 \mathrm{kv}$; $\mathrm{cw} \mathrm{x}$-ray tube current, $3 \mathrm{~mA}$; charging voltage, $16 \mathrm{kV}$. The pressure ratio of $\mathrm{C}_{4} \mathrm{H}_{10} / \mathrm{SF}_{6}$ is $7 / 73$.

As shown in Fig. 3, since the main discharge was unsettled without any preionization, the laser output energy was weak ( $<5 \mathrm{~mJ})$, and lasing pressure was less than 100 Torr due to the onset of arcing. When applying $\mathrm{cw} x$ radiation, however, the maximum laser energy was increased about 3 times larger than without applying $\mathrm{cw} x$ radiation and the total pressure producing the maximum laser energy was 120 Torr. The uniform glow discharge could be obtained at pressures less than 300 Torr with $x-r a y$ illumination. Similar preionization effect was also observed in an $\mathrm{N}_{2}$ laser. Thus, the illumination of $\mathrm{CW} x-$ ray seems to be capable of establishing arc-free discharge, so that this illumination can work as a preionizer of gas discharge lasers.

Since the dose rate of the $\mathrm{cw} x$-ray generator is easily controllable, the

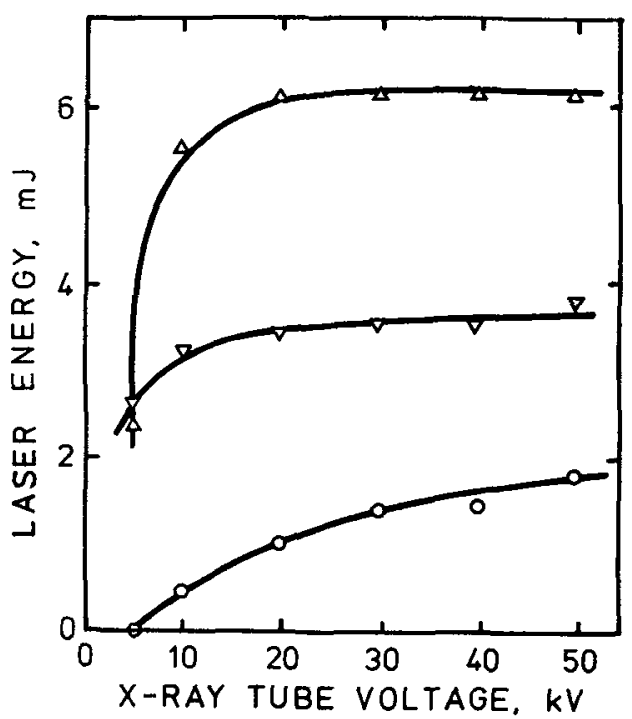

FIG. 4. Graphs of $\mathrm{C}_{4} \mathrm{H}_{10} / \mathrm{SF}_{6}$ laser energy versus $x$-ray tube voltage for various total pressures. cw $x$-ray tube current, $2 \mathrm{~mA}$; charging voltage, 16 $\mathrm{kV}$. The pressure ratio of $\mathrm{C}_{4} \mathrm{H}_{10} / \mathrm{SF}_{6}$ is $7 / 73$. Total pressure, $\nabla$ : 40 Torx; $\Delta$ : 120 Torr; 0 : 200 Torr.

laser output energy from HF laser was measured as a function of its dose rate, corresponding to the initial preionization number density. The initial electron number density was estimated from the ele- 
ctron-ion kinetic equations. In the case of $\mathrm{HF}\left(\mathrm{C}_{4} \mathrm{H}_{10} / \mathrm{SF}_{6}\right)$ laser, the existence of electronegative $\mathrm{SF}_{6}$ gas induced the electron-ion kinetic equations to be complicated and then it is impossible to estimate the initial electron number density due to appearance of the unknown electron-ion loss coefficient for $\mathrm{SF}_{6}$. However, since the electron-ion production rate is in proportion to $x$-ray tube voltage, it is reasonable that the initial electron number density produced by $\mathrm{cW}$ $x$-ray irradiation increases with increasing the $x$-ray tube voltage. The HF laser energy versus the $c w$ x-ray tube voltage against various mixture pressures are plotted in Fig. 4. This experiment was carried out under conditions where the energy stored in the discharge circuit was kept constant. On the curves of total pressures of 40 Torr and 120 Torr, the laser energy tends to saturate at tube voltages in excess of $20 \mathrm{kV}$. On the curve of 200 Torr, however, the laser energy increases almost linearly with increasing the cw $x$-ray tube voltage. This behavior indicates that the high pressure gas requires a sufficient preionization electron number density to create volumetrically-uniform avalanche-discharge.

Then, the cw $x$-ray preionizer is found to control the laser output, and/or minimize the input power into the preionizer for maximization of system efficiency of the laser device.

Since $x$-ray photons have a characteristic of long penetration, the cw $x$-ray preionizer has many advantages for gas

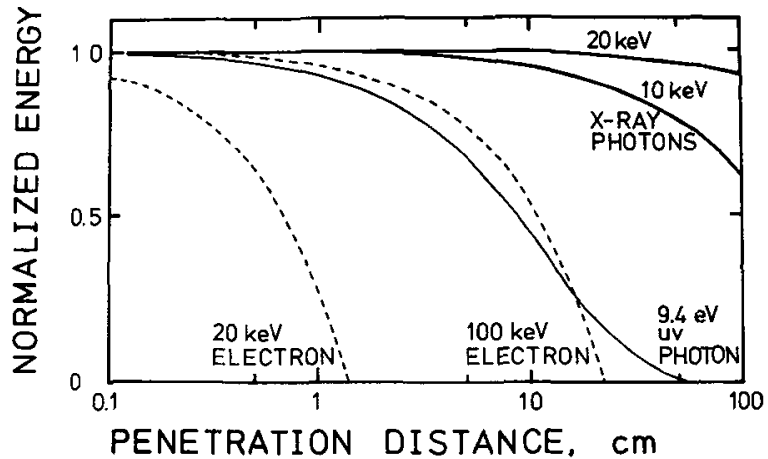

FIG. 5. The rough estimation of the penetration distance of photons and electrons for various energies. The particle energies are normalized by $I$ at distance equal to $0 . \mathrm{N}_{2}$ gas $\left(1 \mathrm{~atm}, 0{ }^{\circ} \mathrm{C}\right)$ is used in this estimation.

laser systems. The rough estimation of the penetration distance of photons and electrons for various energy transmitting through $\mathrm{N}_{2}$ gas is shown in Fig. 5. The ordinate is the normalized particle energY. In this estimation, it is assumed that the absorption cross section of electrons and photons against the gas remain constant with transmitting through the gas. Then, the calculated penetration distance of electron and $\mathrm{x}$-ray photons except uv photons is over estimated. However, by comparing the penetration distance and the deposit energy delivered for ionization of these particles, this estimation is available. As can be seen in Fig. 5, it is clear that the 20-keV photons (i.e. x-ray phoyons) transmit longer distance than the same energy electrons and uv photons $(130 \mathrm{~nm}=$ $9.4 \mathrm{ev}), 7,8,9$ At the same time, fraction of the deposit energy for gas ionization by $\mathrm{x}$-ray photons par unit penetration distance is smaller than that of electrons and uv photons. Thus, on the assumption that the incident energy from various preionizers to 
laser gas is kept constant, it is impossible to satisfy simultaneously long penetration of preionization and the large deposited energy delivered for preionization. However, we observed $5 \times 10^{7} \mathrm{~cm}^{-3}$ of the electron number density in $\mathrm{N}_{2}$ gas of 50 Torr produced by the $\mathrm{cw} x$-ray photons at $35 \mathrm{~cm}$ apart from the $\mathrm{x}$-ray generator with $150 \mathrm{~W}$ $(50 \mathrm{kV}, 3 \mathrm{~mA})$ of $\mathrm{cW}$-ray generator input? This number density is large enough to precondition the gas discharge for the highpressure lasers.10 Accordingly, the cw $\mathrm{x}-$ ray preionizer has a potential of long penetration depth together with sufficient preionization establishing the uniform glow discharge.

Since the cw $x$-ray preionizer has long mass penetration, this makes it possible to separate spatially the preionizer from the laser chamber by an appropriate $x$-ray window. Therefore, the problem of gas contamination and degradation induced by the preionizer put together with discharge region in the laser gas (e.g. uv flash preionizer) can be solved, which became serious in the H.R.R. closed-cycle laser. Moreover, the long penetration also provides high scalability. For instance, the CW $x$-ray preionizer used in these experiments is expected to be capable of preionizing large-scale lasers with their discharge dimensions in excess of $30 \times 30 \times$ $100 \mathrm{~cm}^{3}(901)$. When this preionizer is used for such a large-scale laser, the input power of the cw $x$-ray generator is negligible in comparison with the avarage input power of H.R.R. main discharge. The cw $x$-ray preionizer can be adaptable for huge-volume preionization (>90 1) by means of the use of several cw x-ray generators. The long lifetime of the $\mathrm{cw} x$-ray generator is suitable for the practical H.R.R. lasers, moreover, the repetition rate of laser action is not limited up to $10^{5}$ PPS by this preionizer.

The use of the $\mathrm{CW}$ preionization source, such as a cw $x$ radiation for a pulsed-discharge laser has never been reported.

This type of preionization allows elimination of the adjustment of the time delay between pulsed preionization and main discharge. For such lasers in which electronegative gases are contained, as rate-gas halide lasers, and/or for highpressure gas lasers, the disappearance rate of initial electrons produced by a pulsed preionization source is extremely rapid, so that in these lasers troublesome optimization of these delay time may become very sensitive. Therefore, the use of a continuous-wave preionization source for these lasers has the advantage of being delay-time adjustment-free.

IV. SUMMARY

In surmary, we have revealed experimentally the effect of preionization by $\mathrm{cW}$ $x$ radiation on an $\mathrm{HF}$ laser and have concluded that $\mathrm{cw} x$-ray preionizer is very suitable for large-scale H.R.R. closedcycle gas lasers ${ }^{11,12}$ and especially for high-pressure lasers and/or those containing electronegative gases, such as highpressure rare-gas halide excimer lasers, 


\section{REFERENCES}

Is. Sumida, M. Obara, and T. Fujioka, Appl. Phys. Lett. 33, 913 (1978).

${ }^{2}$ Shao-Chi Lin and J. I. Levatter, Appl. Phys. Lett. 34,505 (1979).

${ }^{3}$ G. L. Clark, Encyclopedia of $x$ Rays and Gamma Rays (Reinhold, New York, 1963), p. 1098.

"Hitachi, Lta., Japan (private communication).

${ }^{5}$ T. Arai, M. Obara, and T. Fujioka, J. Appl. Phys. 51,3556 (1980).

${ }^{6}$ T. Arai, M. Obara, and T. Fujioka, Appl. Phys.
Lett. 36,235 (1980).

${ }^{7}$ R. V. Babcock and I. Liberman, and w. D. Partlow, IEEE J. Quantum Electron., QE-12, 29 (1976).

${ }^{8}$ Atomic Data Tables, 5, 51 (1973).

${ }^{9}$ ICRU Report 21 (1972).

${ }^{10}$ A. J. Palmer, Appl. Phys. Lett. 31, 138 (1974).

${ }^{11} \mathrm{~J}$. L. Miller, J. Dickie, J. Davin, J. Swingle, and T. Kan, Appl. Phys. Lett. 35, 912 (1979).

${ }^{12}$ T. S. Fahlen, J. Appl. Phys. 49, 455 (1978). 